\title{
Development of a 400 Level 3C Clamped Downhole Seismic Receiver Array for 3D Borehole Seismic Imaging of Gas Reservoirs
}

\author{
Quarterly Reports:
}

April 1, 2002 - June 30, 2002

Björn N.P Paulsson

September 2002

DOE Contract: DE-FC26-01NT41234

Paulsson Geophysical Services, Inc.

1215 West Lambert Road Brea, CA 92821-2819

Phone: 562-697-9711, Cell: 310-489-5594 Fax: 562-697-9773

E-mail: bjorn.paulsson@paulsson.com Website: www.paulsson.com 


\section{DISCLAIMER}

This report was prepared as an account of work sponsored by an agency of the United States Government. Neither the United States Government nor any agency thereof, nor any of their employees, makes any warranty, express or implied, or assumes any legal liability or responsibility for the accuracy, completeness, or usefulness of any information, apparatus, product, or process disclosed, or represents that its use would not infringe privately owned rights. Reference herein to any specific commercial product, process, or service by trade name, trademark, manufacturer, or otherwise does not necessarily constitute or imply its endorsement, recommendation, or favoring by the United States Government or any agency thereof. The views and opinions of authors expressed herein do not necessarily state or reflect those of the United States Government or any agency thereof.

\section{ABSTRACT}

Borehole seismology is the highest resolution geophysical imaging technique available to the oil and gas industry for characterization and monitoring of oil and gas reservoirs. However, the industry's ability to economically do high resolution 3D imaging of deep and complex gas reservoirs using borehole seismology is currently frustrated by the lack of the acquisition technology necessary to record the large volumes of the high frequency, high signal-to-noise-ratio borehole seismic data needed to do 3D imaging. This proposal takes direct aim at this shortcoming. P/GSI is developing a 400 level 3C clamped downhole seismic receiver array for borehole seismic 3D imaging. This array will remove the acquisition barrier to record the necessary volumes of data to do high resolution 3D VSP or 3D cross well seismic imaging.

3D VSP and long range Cross-Well Seismology (CWS) are two of the borehole seismic techniques that will allow the Gas industry to take the next step in their quest for higher resolution images of the gas reservoirs. Today only a fraction of the original Oil or Gas in place is produced when reservoirs are considered depleted. This is primarily due to our lack of understanding of the detailed compartmentalization of the oil and gas reservoirs.

The 400 level 3C borehole seismic receiver array will allow for economic use of 3D borehole seismic imaging for reservoir characterization and monitoring. By using $3 \mathrm{C}$ surface seismic or $3 \mathrm{C}$ borehole seismic sources the 400 level receiver array will furthermore facilitate $9 \mathrm{C}$ reservoir imaging. The $9 \mathrm{C}$ borehole seismic data will provide $\mathrm{P}$, $\mathrm{SH}$ and SV information for imaging of the complex deep gas reservoirs and allow quantitative prediction of the rock and the fluid types. The data quality and the data volumes from a 400 level $3 \mathrm{C}$ array will allow us to develop the data processing technology necessary for high resolution reservoir imaging. 


\section{TABLE OF CONTENTS}

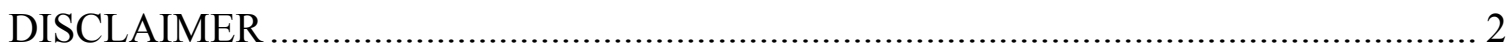

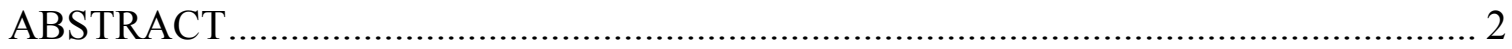

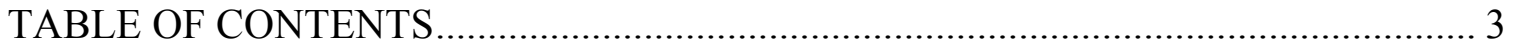

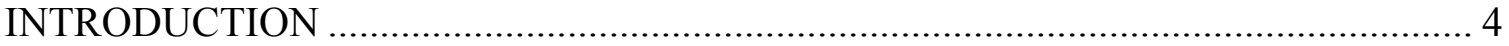

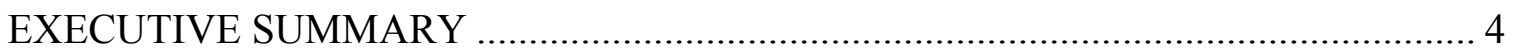

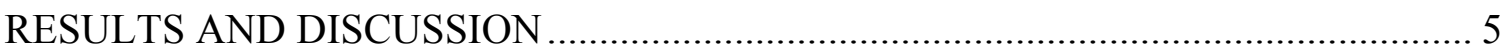

PHASE I - Design and Manufacturing phases for the 400 level, 3C Downhole Seismic

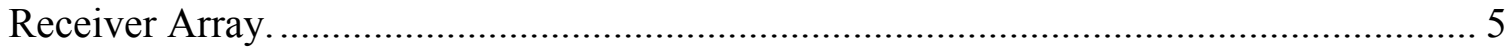

Task 1.0 Design Receiver Array ....................................................................... 5

Task 1.1 Design the array to work with wellhead pressure control equipment.......... 5

Task 1.2 Design the cables and the geophone pods for the 400 level receiver arrays.5

Task 1.3 Design the tubing required for deploying the 400 level geophone array..... 6

Task 1.4 Design the Geophone pod housings for the receiver array .......................... 6

Task 1.5 Design the miscellaneous deployment equipment for the receiver arrays... 7

Task 1.6 Design the winches for the cables and the geophone pods.......................... 7

Task 1.7 Design the trailers used to transport the 400 level receiver array system to

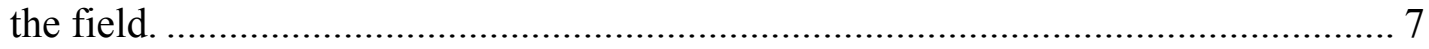

Task 2.0 Manufacture Receiver Array .................................................................. 8

Task 2.1 Manufacture the five sub arrays for the 400 level analog receiver array..... 8

Task 2.2 Manufacture the tubing required for deploying the geophone array............. 8

Task 2.3 Manufacture the Geophone pod housings..................................................... 9

Task 2.4 Manufacture the miscellaneous deployment equipment for the arrays........ 9

Task 2.5 Manufacture the winches for the cables and the geophone pods................. 9

Task 2.6 Manufacture the trailer used to transport the 400 level receiver array

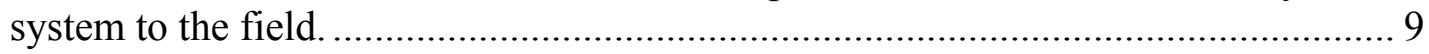

Task 3.0 Develop Data Processing and Imaging Software ...................................... 10

Task 3.1 -- Software Design .............................................................................. 10

Task 3.2 -- Software Framework ………………............................................... 10

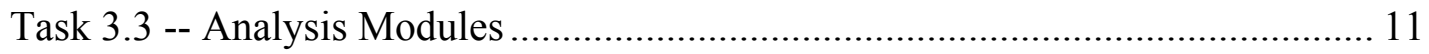

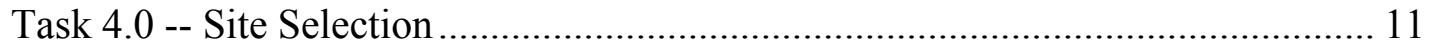

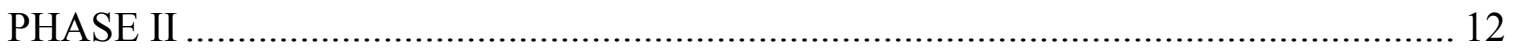

Task 5.0 -- Field Testing and Data Analysis.......................................................... 12

Task 5.1 - Deployment of the 400 level receiver array in borehole seismic survey 12

Task 5.2 -- Data Analysis and Interpretation ............................................................ 13 


\section{INTRODUCTION}

This document reports on the development of a long borehole seismic array. A long borehole seismic array is essential to economically record enough data to do 3D VSP imaging or large data volume cross well imaging.

Traditionally seismic arrays have been deployed using seven conductor wireline technology. The seven conductor wirelines have a limited data band width, limited mechanical strength and are limited to operations in wells which are vertical or with limited deviation. The array described in this document overcomes the limitations with wireline deployed receiver arrays.

\section{EXECUTIVE SUMMARY}

In this report period P/GSI successfully finished the assembly and the initial testing of the 400 level borehole seismic array. In this report period P/GSI continued to develop the software for processing the borehole seismic data. Much of the work relates to building data management tools for handling the large amounts of data generated by the large borehole seismic arrays.

In the previous report, for the periods up to March 31, 2002, periods P/GSI concluded the design and the manufacturing of the 400 level borehole seismic receiver array. The design was a refinement and update of the existing P/GSI 80 level array. The following tasks were concluded in the previous period:

1.0 Design Receiver array.

1.1 Design the array to work with wellhead pressure control equipment.

1.2 Design the cables and the geophone pods for the 400 level receiver arrays.

1.3 Design the tubing required for deploying the 400 level geophone array.

1.4 Design the Geophone pod housings for the receiver array.

1.5 Design the miscellaneous deployment equipment for the receiver arrays.

1.6 Design the winches for the cables and the geophone pods.

1.7 Design the trailers used to transport the 400 level receiver array system to the field.

2.0 Manufacture Receiver array.

2.1 Manufacture the five sub arrays for the 400 level analog receiver array.

2.2 Manufacture the tubing required for deploying the geophone array.

2.3 Manufacture the Geophone pod housings.

2.4 Manufacture the miscellaneous deployment equipment for the arrays.

2.5 Manufacture the winches for the cables and the geophone pods.

2.6 Manufacture the trailer used to transport the 400 level receiver array system to the field.

3.0 Develop Data Processing and Imaging Software

3.1 Software Design

3.2 Software Framework

3.3 Analysis Modules 
The tasks during this report period are primarily design and manufacturing tasks. During the upcoming report periods we will report on the results deploying the 400 level tubing deployed array and processing of the data using the developed software.

\section{RESULTS AND DISCUSSION}

\section{PHASE I - Design and Manufacturing phases for the 400 level, 3C Downhole Seismic Receiver Array.}

\section{Task 1.0 Design Receiver Array}

Task 1.0 Plan

There are a large number of issues to resolve before the manufacturing of the 400 level array can start. Our current system is operational to $125^{\circ} \mathrm{C}\left(250^{\circ} \mathrm{F}\right)$ to $10,000 \mathrm{ft}$. High temperature components must be selected that can reliably operate to at least $150^{\circ} \mathrm{C}$ $\left(300^{\circ} \mathrm{F}\right)$ to achieve $25,000 \mathrm{ft}$. Some of the components are already commercially available and can immediately be incorporated into the high temperature array. High temperature geophones that operate to a temperature of $200^{\circ} \mathrm{C}\left(400^{\circ} \mathrm{F}\right)$ are available from several manufacturers. We anticipate that the design can be achieved in 3 months. It is an aggressive schedule but achievable because we can draw from the experience building the current $250^{\circ} \mathrm{F}$ receiver array.

Task 1.0 Accomplishments

P/GSI designed the 400 level borehole seismic array starting using P/GSI previous borehole seismic array. The cable was updated using a new plastic material and the geophone pods were manufactured in steel rather than polyurethane.

\section{Task 1.1 Design the array to work with wellhead pressure control equipment.}

\section{Task 1.1 Plan}

Interview operators of gas fields to gain a full understanding of the required functions of the array to be acceptable for deployment in a well with high temperatures and pressures. Incorporate design of wellhead pressure control equipment into the design of the 400 level, 3-component clamped receiver array.

Task 1.1 Accomplishments

P/GSI has developed a well head feed through that simultaneously hold the production tubing and the cables. This will allow us to record data in a well that is pressurized.

Task 1.2 Design the cables and the geophone pods for the 400 level receiver arrays. 


\section{Task 1.2 Plan}

Design the analog cables for the 400 level receiver arrays. We will design the $25,000 \mathrm{ft}$ analog cables with a twisted pair for each geophone. The $25,000 \mathrm{ft}$ of analog data transmission has met with general acceptance among geophysicists that have been consulted on this key issue. In surface seismic surveys analog lines as long as $50,000 \mathrm{ft}$ were and are routinely used. The borehole is furthermore a very quiet environment electrically so very little noise should couple into the arrays. The lead in cable with 126 twisted pairs in our current array is $10,000 \mathrm{ft}$ long with no apparent degradation in data quality.

\section{Task 1.2 Accomplishments}

The cable design was modified to accommodate 252 twisted pairs, up from the previous 126 pairs, using magnet wire that connect the geophones in the geophone pods with the digitizing equipment on the surface. This design change was accomplished without changing the outside diameter of the cable. The 252 twisted pair cable allow us to deploy $803 \mathrm{C}$ levels, 240 channels, on one cable. A new type of polyurethane, Perlthane from Dow Chemical, was chosen as the jacket material of choice. This new polyurethane allows us to operate the cables up to an ambient temperature of $300^{\circ} \mathrm{F}$.

The geophone pod design was changed to include a steel housing and steel end caps. These changes increase significantly the pressure rating of the geophone pods. The estimated pressure rating of the new design is $15,000 \mathrm{psi}$ - high enough rating for a receiver array deployment to a depth of $30,000 \mathrm{ft}$ in water. We have successfully tested the new design to a pressure of 10,000 psi in a pressure chamber in a 6 hour test.

\section{Task 1.3 Design the tubing required for deploying the 400 level geophone array.}

\section{Task 1.3 Plan}

Design the tubing required for deploying the 400 level geophone array. In particular we need to review the weight vs tubing strength for the array.

Task 1.3 Accomplishments

After reviewing the different options for tubing a 1.660" tubing was selected as the tubing for the 400 level array. We selected an EUE tubing with $10 \mathrm{Rd}$ threads using an N80 material.

\section{Task 1.4 Design the Geophone pod housings for the receiver array}

\section{Task 1.4 Plan}

Design the geophone pod housings for the receiver array. The geophone pod housings will protect the geophone pods during the deployment of the array and contain the clamping mechanisms for the geophone pods.

\section{Task 1.4 Accomplishments}

The geophone pod housings were redesigned to be able to handle a larger axial load. The estimated strength of the pod housing is now $110,000-120,000 \mathrm{lb}$. In a test the previous 
design failed at a load of 98,000 $\mathrm{lb}$. We plan to test the new design at a certified testing laboratory later in 2002.

Task 1.5 Design the miscellaneous deployment equipment for the receiver arrays.

Task 1.5 Plan

Design all the deployment equipment to safely deploy the receiver arrays in gas wells.

Task 1.5 Accomplishments

A number of miscellaneous types of equipment has been designed or redesigned as part of this project. The types of equipment include:

1. Sheave wheels designed to guide the cables from the winches to the well.

2. Work plate for safely work over the well

3. Specialized tools for attaching the cables to the geophone pod housings.

4. A new bottom assembly for the array.

5. A new top assembly to control and regulate the clamping of the geophones.

6. A new centralizer to protect cable splices has been designed and built.

7. A new cable protection sub designed to protect the cable through BOP's was designed and built.

Task 1.6 Design the winches for the cables and the geophone pods.

Task 1.6 Plan

Design the winches used to deploy the $25,000 \mathrm{ft}$ cables and the geophone pods.

Task 1.6 Accomplishments

The winches for the geophone pod cables was completely redesigned. The new winch has a sturdy frame which allows lifting and handling the unit without risking damaging the cable. The winch design also incorporated a foot switch which allows one person to both operate the spool and control the cable spooling. The spool can hold up to $20,000 \mathrm{ft}$ of cable.

\section{Task 1.7 Design the trailers used to transport the 400 level receiver array system to the field.}

\section{Task 1.7 Plan.}

To design the field trailers used to store, transport and field the deployment system for the 400 level array.

\section{Task 1.7 Accomplishments}

The field unit was completely redesigned, compared with our old unit, allowing secure transport and handling of the equipment to the field sites. The field unit also serves as the operators cab, with power, heating and cooling built in, during the deployment and acquisition of the borehole seismic data. 


\section{Task 2.0 Manufacture Receiver Array}

Task 2.0 Plan

The overall objective is to manufacture the various components for the 400 level receiver array. The 12 months manufacturing period of this equipment is aggressive but achievable with firm planning and experienced project management.

Task 2.0 Accomplishments

The entire system was completed by February 28, 2002.

\section{Task 2.1 Manufacture the five sub arrays for the $\mathbf{4 0 0}$ level analog receiver array.}

Task 2.1 Plan

The key components of the 400 level receiver array are the five 80 level sub arrays. These five arrays will be manufactured using high temperature standard materials. The arrays are using analog transmission of the data to the surface and the data is recorded on a standard surface seismic recording system like an I/O II 1,200-channel 24 bit recording system.

\section{Task 2.1 Accomplishments}

Five 80 level receiver arrays, for a total of 400 levels, were manufactured by Input/Output, Inc. for P/GSI. P/GSI provided Input/Output, Inc. with the fundamental specifications and the design of the cable and geophone pods. Each cable is $10,000 \mathrm{ft}$ long. Input/Output also manufactured an additional 10,000 ft of lead in cable for deeper operations down to $20,000 \mathrm{ft}$.

\section{Task 2.2 Manufacture the tubing required for deploying the geophone array.}

\section{Task 2.2 Plan}

One of the key features with the P/GSI 400 level clamped receiver array is that it is deployed on oil field production tubing or possibly on oil field drill pipe. The tubing used successfully with the current $10,000 \mathrm{ft}$ system is small diameter production tubing. The production tubing is the strength member in the system. It also provides the conduit for the fluid pressure to inflate the packers to clamp the 400 levels of $3 \mathrm{C}$ geophones. The current P/GSI 80 level array does not include the feature of allowing tripping in through pressure control equipment. We will incorporate the same equipment in our receiver array deployment system used to trip in Electric Submersible Pump (ESP) systems in live wells.

\section{Task 2.2 Accomplishments}

$\mathrm{P} / \mathrm{GSI}$ had a special run of tubing manufactured to allow deployment in one or several wells. The tubing is manufactured for P/GSI with a length specification of $+/-1 / 4$ ". The tight specification on the length of the tubing provide for a highly accurate positioning of the receivers in the borehole. The tubing otherwise is a standard API tubing so all the handling of the equipment can be performed with standard oil field tools for tubular. We 
now have enough tubing to deploy our 400 level array in one, two, three, four or five wells simultaneously.

\section{Task 2.3 Manufacture the Geophone pod housings.}

\section{Task 2.3 Plan}

The geophone pod housings fulfill a dual purpose. The first is to protect the pods during the deployment into the well. The second is to provide the clamping functions for the pod. The clamping function is achieved using a small packer that is inflated through the tubing.

Task 2.3 Accomplishments

330 geophone pod housings were manufactured using an updated design. Together with the existing 88 pod housings, for a total of 418 , provide for enough geophone pod housings to deploy a 400 level array distributed in one, two, three, four or five wells.

\section{Task 2.4 Manufacture the miscellaneous deployment equipment for the arrays.}

\section{Task 2.4 Plan}

A large number of miscellaneous pieces of equipment must be manufactured to support the deployment and operation of the 400 level receiver array. The task here is to make sure all the necessary components are manufactured to make the array fully operational in a safe manner.

Task 2.4 Accomplishments

We manufactured redesigned sheave wheel for the safe deployment of the receiver arrays. Other items manufactured include a bottom assemblies that contain the valves, the top assemblies that are used to pressurize the arrays, work well plates for work over the wells.

Task 2.5 Manufacture the winches for the cables and the geophone pods.

\section{Task 2.5 Plan}

To handle the five 25,000 feet of cable with the geophone pods five winches must be manufactured. Each winch will hold the cable for one 80 level sub array.

Task 2.5 Accomplishments

We built five winches each capable of holding up to $20,000 \mathrm{ft}$ of downhole geophone cable. The manufacturer of the spool was working with P/GSI to incorporate P/GSI experience from the field operations into the new design.

Task 2.6 Manufacture the trailer used to transport the 400 level receiver array system to the field.

Plan 2.6 Plan. 
Manufacture the two field trailers that will be used to transport the 400 level receiver array system to the field.

\section{Plan 2.6 Accomplishments}

We decided that we need a separate field unit for each geophone cable spool. A $25 \mathrm{ft}$ field unit was designed and four of these units were built. For the fifth spool we used an existing field unit. The field units are divided into two sections. One section holds the spool with geophone cable and the other section is the spool operators cab. The operators $\mathrm{cab}$ is both heated, for cold weather operations and air conditioned for warm weather operation. Each of the five field units have been equipped with a diesel engine powered $13 \mathrm{~kW}$ generator so the unit is self contained with regard to power.

\section{Task 3.0 Develop Data Processing and Imaging Software}

$\underline{\text { Task 3.0 Plan }}$

$\mathrm{P} / \mathrm{GSI}$ will develop advanced data processing and imaging software modules for the 9C borehole seismic data. The processing system shall be closely linked to the acquisition system, and shall be able to handle terabyte $9 \mathrm{C}$ prestack seismic data volumes.

\section{Task 3.0 Accomplishments}

A number of software modules have been started and is currently being tested on real data recorded in the past. Software modules currently under the development include automated $3 \mathrm{C}$ rotation of all the data from deviated wells using selected source point to orient the receivers. Other software under the development is 3D velocity estimation and automated submission of tasks to a parallel computer.

\section{Task 3.1 -- Software Design}

Task 3.1 Plan

$\mathrm{P} / \mathrm{GSI}$ shall design the processing and imaging code for high resolution large data volume 9C borehole seismic data. Initial testing will be performed to aid in design of the object types, their use and communication patterns. Interfaces will be designed to allow for communication with other systems in a secure and speedy manner. The system will be designed to be fast, reliable, fault tolerant, and portable.

\section{Task 3.1 Accomplishments}

P/GSI has completed most of the tasks of designing the 9C software. The software is being tested on real data and the design is judged from the results of the images and the information content of the results.

\section{Task 3.2 -- Software Framework}

Task 3.2 Plan

$\mathrm{P} / \mathrm{GSI}$ shall implement the data flow management and infrastructure for $9 \mathrm{C}$ data volumes which will be based on a multi-threaded object flow, which allows for fast parallel as 
well as pipelined computation on suitable computer hardware. This software infrastructure keeps track of the data types, origin, and destinations.

Task 3.2 Accomplishments

$\mathrm{P} / \mathrm{GSI}$ is in the process of concluding setting up data flow routines to process $3 \mathrm{C}$ and $9 \mathrm{C}$ data on parallel computer clusters. The design and programming of the data pipe line is a critical part of this process. This pipe line is now almost complete.

\section{Task 3.3 -- Analysis Modules}

$\underline{\text { Task } 3.3 \text { Plan }}$

P/GSI will implement the seismic data analysis modules that are essential for high-quality 9C data processing, including but not limited to: modules for 9C wave field separation techniques; modules for 3D velocity model estimation; 3D imaging modules to create 3D images from either the separated data or the pre-stack data objects; and modules for generating 3D fluid flow attributes through the analysis of AVO/AVIS and other advanced analysis on the 3D data volume. The recipient shall ensure the export functionality of partially or entirely processed data, and will implement the linkage and accessibility to external software systems. Data processing modules will be prototyped in the ProMAX data processing system for appraisal of the effectiveness of the module. The above modules will be implemented within the existing P/GSI proprietary borehole seismic processing system.

\section{Task 3.3 Accomplishments}

$\mathrm{P} / \mathrm{GSI}$ is in the process of developing the software modules for $3 \mathrm{C}$ and $9 \mathrm{C}$ wave field separation and $3 \mathrm{D}$ velocity model estimation. All the modules are developed and tested on real borehole seismic 3D and 4D data using 3C and in the future 9C data.

\section{Task 4.0 -- Site Selection}

\section{$\underline{\text { Task 4.0 Plan }}$}

P/GSI will work with operators of gas fields to perform at least one but preferably several test and demonstration surveys with the developed hardware to demonstrate how the $3 \mathrm{C}$ or 9C 3D borehole seismic data can characterize heterogeneous and fractured reservoirs. We will also demonstrate how the data can be used to characterize the fluid in the gas reservoirs that are imaged. We will deploy either a surface $3 \mathrm{C}$ vibrator or P/GSI's downhole axial vibrator and an orbital vibrator borrowed from LBL and the 400 level array in several configurations depending on the imaging target of the gas field operator and the wells available for tool deployment. The dataset will be collected in a well or between two wells in a known fractured reservoir, and the results will be correlated with other measurements and production information.

$\mathrm{P} / \mathrm{GSI}$ will work with a gas production company to determine the specific objectives for 9C 3D VSP and/or cross well seismic survey(s). P/GSI will work with the gas producer to identify suitable wells, by reviewing geophysical logs, temperature logs, and production 
information. The site(s) will be chosen to optimize the unique capabilities of the 400 level receiver array and companion software.

Prior to Phase II work, the recipient shall submit to DOE for approval the proposed test sites and site characterization information.

Task 4.0 Accomplishments

A search for a test site was started during this test period.

\section{PHASE II}

\section{Task 5.0 -- Field Testing and Data Analysis}

\section{Task 5.0 Plan}

The recipient shall perform multiple tests of the 400-level receiver array and companion processing and imaging software in selected wells, in a gas-producing field where natural fractures are known to occur. The objective is to generate data and gain experience in the deployment and utility of 3D data sets from the 400 level downhole receiver array.

\section{Task 5.0 Accomplishments}

One of the arrays was used for an offshore seismic survey in California. An industry record 7.5 million traces was recorded. Four of the arrays were used for an onshore survey for BP in Alaska. A record breaking 3.0 million traces, for an onshore survey, were recorded in this survey.

\section{Task 5.1 - Deployment of the 400 level receiver array in borehole seismic survey}

\section{Task 5.1 Plan}

P/GSI shall deploy the 400 level receiver array with either a surface $3 \mathrm{C}$ vibrator and/or $\mathrm{P} / \mathrm{GSI}$ 's downhole axial vibrator and an orbital vibrator. The receiver array shall be deployed to record a 9C 3D VSP and/or 9C cross well seismic mode. Data shall be recorded for analysis and interpretation. This data will allow us to map anisotropic properties of the reservoir and further refine the reservoir image.

The purpose is to demonstrate the function and utility of the large 400 level, 3 component, clamped receiver arrays in either 9C 3D VSP mode or 9C cross well seismic mode.

Task 5.1 Accomplishments

Two test surveys were recorded during this period. The system performed flawlessly recording data with outstanding quality. 


\section{Task 5.2 -- Data Analysis and Interpretation}

\section{Task 5.2 Plan}

P/GSI shall perform data processing, imaging, and interpretation of the 9C 3D data acquired in the field test. The resulting information will be used to evaluate fracture density and fluid content of the reservoir. The ultimate objective is to generate an interpreted data set from a fractured gas reservoirs

\section{Task 5.2 Accomplishments}

There was no activity on this task during this report period. 